Original Article

\title{
NOVEL SELECTIVE SPECTROPHOTOMETRIC METHODS FOR THE DETERMINATION OF METHIMAZOLE IN PURE FORM AND IN PHARMACEUTICAL FORMULATION
}

\author{
MALAK Y. AL BATHISH', AZZA A. GAZY², MARWA K. EL JAMAL² \\ 1,2Department of Pharmaceutical Technology, Faculty of Pharmacy, Beirut Arab University, Beirut, Lebanon \\ Email: malak.albathish@gmail.com
}

Received: 16 Sep 2019, Revised and Accepted: 12 Dec 2019

\section{ABSTRACT}

Objective: To develop and validate new, selective spectrophotometric colorimetric analytical methods for the quantification of methimazole in its pure form and in its pharmaceutical preparations.

Methods: Method A is based on the oxidation of methimazole with potassium permanganate in alkaline medium, the manganate ion produced was measured at $\lambda_{\max }=610 \mathrm{~nm}$. Method $B$ is a kinetic determination of methimazole using fixed-time method based on the oxidation of methimazole using known excess of cerium (IV) nitrate in acidic medium and assessing the unreacted Ce (IV) by adding a fixed amount of methyl orange and measuring the absorbance of the resultant solution at $\lambda_{\max }=507 \mathrm{~nm}$ which is equivalent to the unreacted methyl orange. The reaction conditions and analytical parameters are investigated and optimized. Method validation was carried out according to ICH guidelines in terms of linearity, LOD, LOQ precision, and accuracy.

Results: Beer's law is obeyed in the range of $1.50-15.00 \mu \mathrm{g} / \mathrm{ml}$ for method A and $0.25-3.00 \mu \mathrm{g} / \mathrm{ml}$ for method B. The developed methods were subjected to the detailed validation procedure. The proposed spectrophotometric methods were applied for the determination of the methimazole in its pure form and in its pharmaceutical formulation. The percentage recoveries were found to be $100.82 \%$ and $99.85 \%$ in the pharmaceutical formulation for the two proposed methods, respectively.

Conclusion: Both developed spectrophotometric methods, considered as green analytical chemistry, were found to be novel, highly selective and can be applied for the quality control of methimazole in its pure form and in its pharmaceutical formulation based on the simplicity, applicability of the parameters, accessibility of the reagents employed and reasonably low time of analysis.

Keywords: Methimazole, Spectrophotometric methods, Potassium permanganate, Cerium (IV) nitrate, Methyl orange

(C) 2020 The Authors. Published by Innovare Academic Sciences Pvt Ltd. This is an open-access article under the CC BY license (http://creativecommons.org/licenses/by/4.0/) DOI: http://dx.doi.org/10.22159/ijpps.2020v12i2.35715. Journal homepage: https://innovareacademics.in/journals/index.php/ijpps

\section{INTRODUCTION}

Methimazole is an imidazole drug used in the management of hyperthyroidism. In the USP, methimazole has been assayed by silver nitrate precipitation method [1]. Various methods based on different analytical procedures have been described in literature for the determination of methimazole including Ultraviolet-Visible (UVVis) spectrophotometry [2-7], derivative spectrophotometry [8], Raman spectroscopy $[9,10]$, resonance light scattering spectroscopy [11], chemiluminescence [12-14], fluorescence $[15,16]$, capillary electrophoresis [17], immunoassay [18], molecularly imprinted biomimetic sensing [19], Thin Layer Chromatography (TLC) [20] and High Performance Liquid Chromatography (HPLC) [21-25]. Methimazole has been also determined using electrochemical methods by using different chemically modified electrodes through introducing various electron mediators on its surface [26-33].

The UV-Vis spectrophotometer is a simple, low-cost instrument. From literature, there are no visible spectrophotometric methods reported for the determination of methimazole using Potassium permanganate nor Cerium (IV) nitrate which encouraged us to develop these methods. In alkaline medium, potassium permanganate is reduced to manganate on which absorbs maximally at $610 \mathrm{~nm}$, whose absorbance is proportional to the concentration of the drug under study [34-36]. However, in acidic medium Cerium (IV) nitrate is one of the most important oxidants. The use of cerium (IV) as an oxidant is either based on the decrease in its yellow colour or indirect measurement of excess cerium (IV) by a reaction with a colour developing dye or reagent. The first method being measured in the UV-region gives rise for several interferences by UV interfering molecules while adopting the second method and measuring in the visible region eliminates such interferences [37-40].

The aim of the present work was to report new, simple and environment-friendly spectrophotometric methods for the determination of methimazole in pure and in pharmaceutical formulations that could be considered superior in comparison with the previously reported methods.<smiles>Cn1cc[nH]c1=S</smiles>

Fig. 1: Structure of methimazole

\section{MATERIALS AND METHODS}

\section{Chemicals and materials}

Methimazole was certified to contain 98.9 \% (Pharmaline, Lebanon).

Tapazole ${ }^{\circledR}$ tablets (Pharmaline, Lebanon), labeled to contain $5 \mathrm{mg}$ methimazole were purchased.

All chemicals and reagents used were of analytical grade; Ammonium Cerium (IV) nitrate (AnalaR), $\mathrm{H}_{2} \mathrm{SO}_{4}$ (Avonchem, $98 \%$ ), $\mathrm{KMnO}_{4}$ (Fluka), Methyl orange (Aldrich chemicals, dye content $\approx 75$ \%), $\mathrm{NaOH}$ (Scott Science UK, purity 98-99\%), distilled water was produced in-house.

\section{Instrumentation}

Jasco V-730 double beam UV-Vis Spectrophotometer interfaced with a computer programmed with Jasco Spectra Manager software that was used for spectrophotometric measurements, spectral acquisition, and elaboration. A pair of $1 \mathrm{~cm}$ quartz cells were used to measure the absorption spectra. 


\section{Preparation of solutions}

\section{Standard stock solution}

Methimazole standard stock solution having the concentrations of $500 \mu \mathrm{g} / \mathrm{ml}$ was prepared using distilled water as a solvent.

\section{Working standard solution}

A calculated volume of methimazole standard stock solution was diluted with distilled water to obtain a concentration of $50 \mu \mathrm{g} / \mathrm{ml}$ for the working standard solution.

\section{Reagents}

Sodium hydroxide solution $(\mathrm{NaOH} 0.5 \mathrm{M})$ was prepared by accurately transferring $20 \mathrm{~g}$ of $\mathrm{NaOH}$ into a $1 \mathrm{~L}$ volumetric flask. The pellets were dissolved and diluted to volume with distilled water.

Potassium permanganate solution $\left(\mathrm{KMnO}_{4} 0.005 \mathrm{M}\right)$ was freshly prepared by accurately transferring $79 \mathrm{mg}$ of $\mathrm{KMnO}_{4}$ into a $100-\mathrm{mL}$ volumetric flask. The powder was dissolved and diluted to volume with distilled water.

Sulphuric acid solution $\left(\mathrm{H}_{2} \mathrm{SO}_{4} 0.5 \mathrm{M}\right)$ was prepared by diluting $27.18 \mathrm{ml}$ of concentrated sulfuric acid (98\%) with distilled water in a $1 \mathrm{~L}$ volumetric flask.

Ammonium Cerium (IV) nitrate solution (50 mg \%) was freshly prepared by accurately weighing $50 \mathrm{mg}$ of Ammonium Cerium (IV) nitrate. The powder was dissolved and diluted to volume with $0.5 \mathrm{M}$ $\mathrm{H}_{2} \mathrm{SO}_{4}$ in a 100 -mL volumetric flask.

Methyl orange solution ( $5 \mathrm{mg} \%$ ) was freshly prepared by accurately weighing $6.7 \mathrm{mg}$ of methyl orange with dye contert75\%. The powder was dissolved and diluted to volume with distilled water in a $100-\mathrm{mL}$ volumetric flask.

\section{Recommended procedure}

\section{Method A}

Aliquots of methimazole working standard solution were transferred into a series of $10-\mathrm{ml}$ volumetric flasks to cover the concentration range stated in table 5 . A volume of $1.5 \mathrm{ml}$ of $0.5 \mathrm{M}$ $\mathrm{NaOH}$ followed by $2 \mathrm{ml}$ of $0.005 \mathrm{M} \mathrm{KMnO}_{4}$ was added to each flask, mixed well and completed to volume with distilled water. The absorbance values of the resultant mixtures were measured at 610 $\mathrm{nm}$ after 2 min against a blank prepared similarly.

\section{Method B}

Aliquots of methimazole working standard solution were transferred into a series of $10-\mathrm{ml}$ volumetric flasks to cover the concentration range stated in table 5 . To each volumetric flask, $1 \mathrm{ml}$ of $50 \mathrm{mg} \%$ Ammonium Cerium (IV) nitrate solution was added. The solutions were mixed well and set aside in darkness for 30 min with occasional swirling. Afterward, $1.2 \mathrm{ml}$ of $5 \mathrm{mg} \%$ methyl orange solution was added to each volumetric flask. After $5 \mathrm{~min}$, the volume was diluted to the mark with distilled water. The absorbance value of each solution was measured against distilled water as blank at $507 \mathrm{~nm}$.

\section{Application to a pharmaceutical preparation}

Ten Tapazole ${ }^{\circledR}$ tablets were accurately weighed and finely powdered. For Method A, a weight equivalent to $5 \mathrm{mg}$ methimazole was dissolved in $10 \mathrm{ml}$ methanol, filtered using Whatman No. 41 filter paper, a volume of $10 \mathrm{ml}$ distilled water was added, the resulting solution was then evaporated using a $70^{\circ} \mathrm{C}$ set water bath to a volume of $5 \mathrm{ml}$. The solution was then quantitatively diluted with distilled water to obtain a solution within the calibration range for the analysis. For Method B, a weight equivalent to $5 \mathrm{mg}$ methimazole was dissolved with distilled water and diluted to 100 $\mathrm{ml}$ with distilled water. The obtained solution was then filtered using Whatman No. 41 filter paper. A convenient aliquot was then considered for the analysis using the proposed method. The amount of methimazole present in the tablet was determined by fitting the resulting absorbance value into the calculated regression equation.

\section{Method validation}

Under the optimized experimental conditions, the developed methods were validated in accordance to the procedures described in ICH guidelines for the following parameters [41]: Linearity, limit of detection (LOD), limit of quantitation (LOQ), precision and accuracy.

\section{Linearity, concentration range, the limit of detection and limit} of quantitation

Linearity was determined in the concentration range of $1.5-15$ $\mu \mathrm{g} / \mathrm{ml}$ and $0.25-3 \mu \mathrm{g} / \mathrm{ml}$ for methimazole in method A and B respectively.

LOD and LOQ were calculated according to the ICH guidelines by using the following formula [41]:

LOD $=3.3 \mathrm{~S}_{\mathrm{y} / \mathrm{x} / \mathrm{b}}$

$\mathrm{LOQ}=10 \mathrm{~S}_{\mathrm{y} / \mathrm{x} / \mathrm{b}}$

Where " $\mathrm{S}_{\mathrm{y} / \mathrm{x}}$ " is the standard deviation of the regression line/residuals and " $b$ " is the slope of the calibration curve.

\section{Accuracy and precision}

In order to assess the accuracy of the proposed methods, the \% recovery of methimazole using the standard addition method at three different concentration levels within the linearity range was determined.

The precision of the proposed methods was assessed by intra-day and inter-day variation studies. The precision was expressed in the form of a percentage relative standard deviation (\%RSD). During intra-day studies, three sample solutions of each concentration were analysed on the same day whereas inter-day studies were determined by analysing three sample solutions of each concentration for three consecutive days.

\section{RESULTS AND DISCUSSION}

\section{Method A}

The oxidation reaction between methimazole and $\mathrm{KMnO}_{4}$ in alkaline medium yields the green-colored manganate radical which absorbs maximally at $610 \mathrm{~nm}$ (fig. 2).

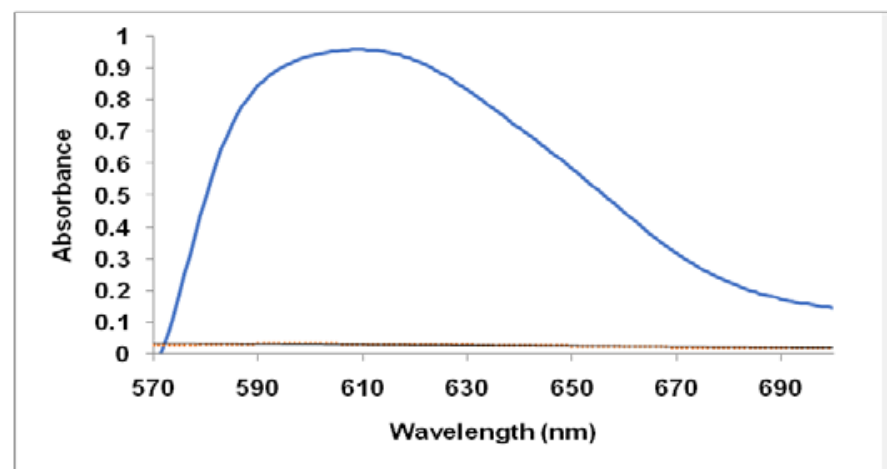

Fig. 2: Absorption spectrum of $15 \mu \mathrm{g} / \mathrm{ml}$ of methimazole with $2 \mathrm{ml} 0.005 \mathrm{M} \mathrm{KMnO}_{4}$ and $1.5 \mathrm{ml} 0.5 \mathrm{M} \mathrm{NaOH}$ 


\section{Optimization of reaction conditions}

Experimental conditions affecting color development were optimized by fixing all conditions and changing one variable at a time. It was found that $2 \mathrm{ml}$ of $0.005 \mathrm{M} \mathrm{KMnO}_{4}$ and $1.5 \mathrm{ml}$ of $0.5 \mathrm{M}$ $\mathrm{NaOH}$ were adequate for stable and maximum absorbance.

\section{Mechanism of the reaction}

The stoichiometry of the reaction between Methimazole and $\mathrm{KMnO}_{4}$ in alkaline medium was determined by adopting the limiting logarithmic method [42]. Two sets of experiments were performed. The first set of experiments was carried out using increasing concentrations of methimazole $\left(8.76 \times 10^{-6}-1.3 \times 10^{-4} \mathrm{M}\right)$ at fixed permanganate concentration $\left(1.5 \times 10^{-3} \mathrm{M}\right)$. The second set of experiments was carried out using increasing concentrations of permanganate $\left(2.5 \times 10^{-4}-1.5 \times 10^{-3} \mathrm{M}\right)$ at fixed methimazole concentration $\left(1.3 \times 10^{-4} \mathrm{M}\right)$. The logarithms of the absorbance values were plotted against the logarithms of the methimazole and $\mathrm{KMnO}_{4}$ concentration in the first and second set of experiments, respectively. Two straight lines were obtained. The slopes of the fitting lines were calculated (fig. 3).

For the calculation of the ratio of the reaction between Methimazole and $\mathrm{KMnO}_{4}$ in alkaline medium, the slope of $\mathrm{KMnO}_{4}$ curve was divided by the slope of the drug curve. It was found that the ratio was 1.439:1.13 pointing out to a ratio of $1: 1 \quad\left(\mathrm{KMnO}_{4}\right.$ to Methimazole). Accordingly, the reaction pathway is suggested to proceed as [7]:

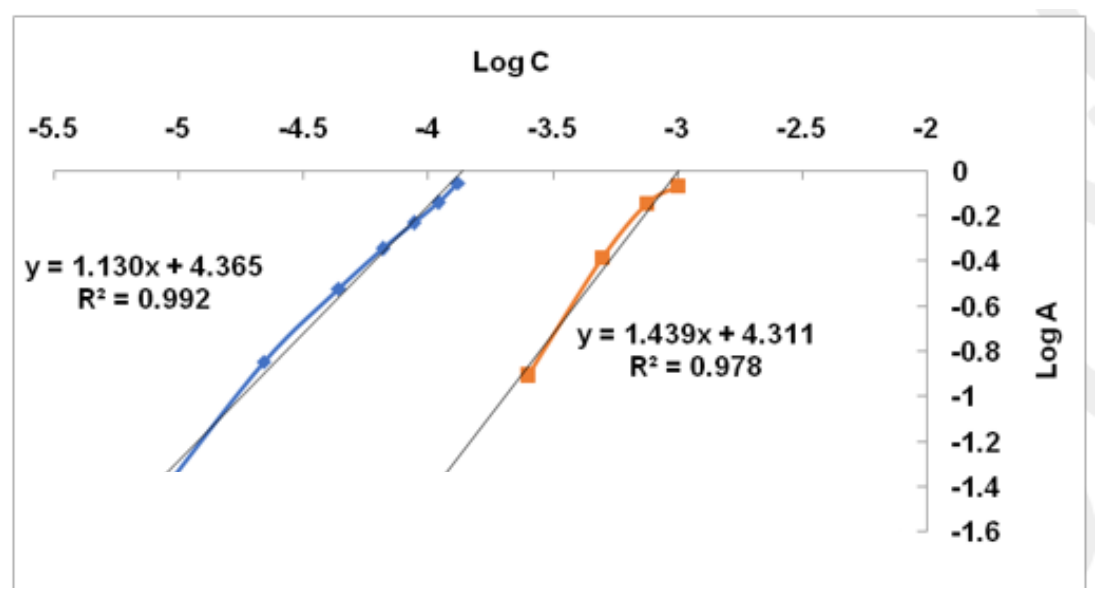

Fig. 3: Limiting logarithmic plot for molar reactivity of methimazole with potassium permanganate

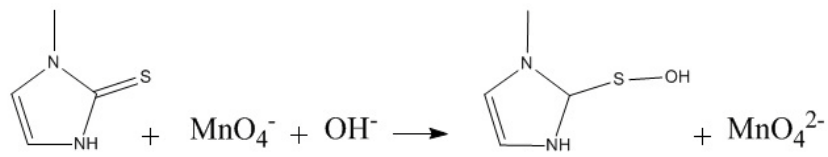

Fig. 4: Suggested mechanism for the oxidation of methimazole by $\mathrm{KMnO4}$ in alkaline medium

According to the suggested mechanism of oxidation, the method is based on the presence of the thiol group which is oxidized by the $\mathrm{MnO}_{4}^{-} / \mathrm{OH}$ system, therefore the absence of this group will retard the reaction pathway. So, it can be concluded that this method can be considered as a stability-indicating method for methimazole determination (7).

\section{Kinetics of the reactions}

It was evident from fig. 5 that the reaction was rapid and became more or less constant after 2 min pointing out to the difficulty to determine the kinetics of the reaction.

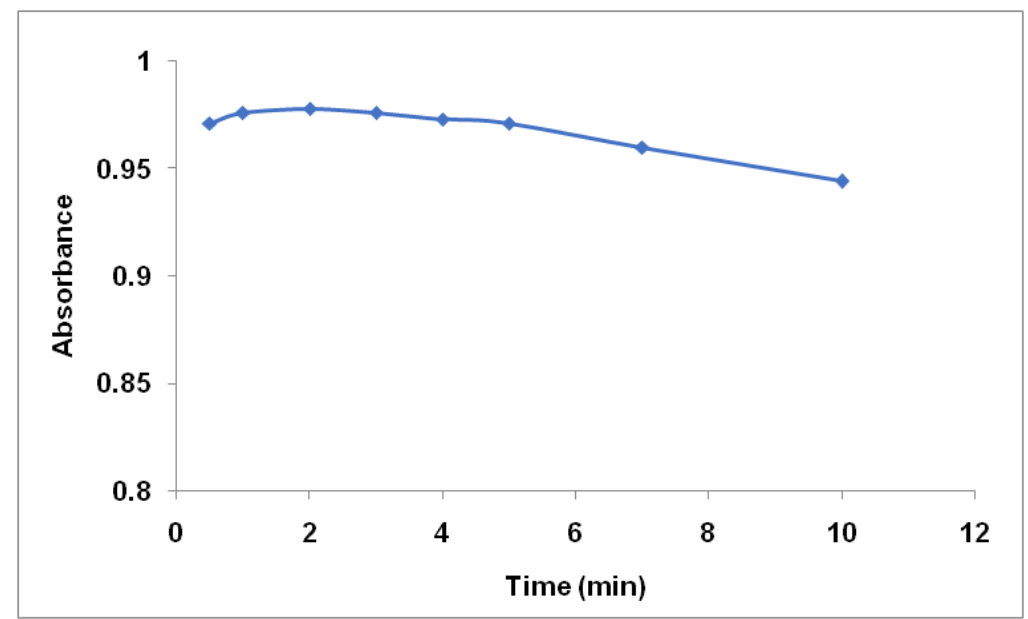

Fig. 5: Effect of time on the absorbance value of the reaction product of $15 \mu \mathrm{g} / \mathrm{ml}$ methimazole at $610 \mathrm{~nm}$ 


\section{Method B}

In this method, Methimazole was allowed to react with a known excess of Ce (IV) nitrate in acidic medium. The unreacted Ce (IV) was reacted with excess methyl orange and the residual methyl orange was determined by absorbance measurement at $\lambda_{\max } 507$ $\mathrm{nm}$ [40]. In the presence of increasing amounts of the oxidant $\mathrm{Ce}$ (IV), the absorbance values of methyl orange decreases. Once the oxidation reaction is assured complete; the unreacted Ce (IV) amount is inversely proportional to the methimazole amount in the sample. According to the scheme below, with increased methimazole concentration, the amount of unreacted Ce (IV) bleaching methyl orange was less and thus the solution absorbance value increases linearly with methimazole concentration (fig. 6).

The proposed reaction mechanism scheme of the indirect determination of methimazole by oxidation with Ce (IV) is shown below [40]:
Methimazole+Ce (IV) excess $\rightarrow$ Methimazole oxidation product $+\mathrm{Ce}$ (III) $+\mathrm{Ce}$ (IV) unreacted

Ce (IV) unreacted $+\mathrm{MO} \rightarrow \mathrm{MO}$ oxidation product + unreacted Methyl orange

\section{Optimization of reaction conditions}

It was found that $1 \mathrm{ml}$ of $50 \mathrm{mg} \%$ cerium (IV) nitrate in acidic medium followed by $1.2 \mathrm{ml}$ of $5 \mathrm{mg} \%$ methyl orange solution after $30 \mathrm{~min}$ at room temperature were optimum to get the stable and maximum color intensity.

\section{Kinetics of the reactions}

The rate of the reaction was dependent on methimazole concentration. Under the optimum conditions described above, the absorbance-time curve was constructed with various drug concentrations in the range of $1-3 \mu \mathrm{g} / \mathrm{ml}$. Both Ce (IV) and methyl orange were kept at their optimal concentration of $5 \mathrm{mg} \%$ and 0.6 mg \%, respectively.

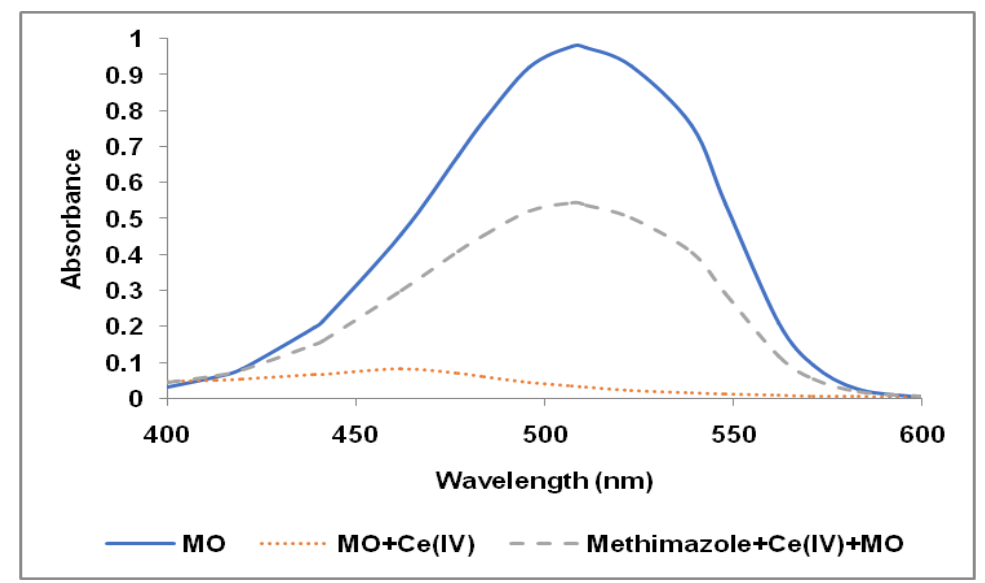

Fig. 6: Absorption spectra of solutions containing (__) $0.6 \mathrm{mg} \%$ methyl orange (MO);(...) $0.6 \mathrm{mg} \% \mathrm{MO}+5 \mathrm{mg} \% \mathrm{Ce}$ (IV) and (---) $0.6 \mathrm{mg} \%$ MO+5 mg\% Ce (IV) $+1.7 \mu \mathrm{g} / \mathrm{ml}$ methimazole

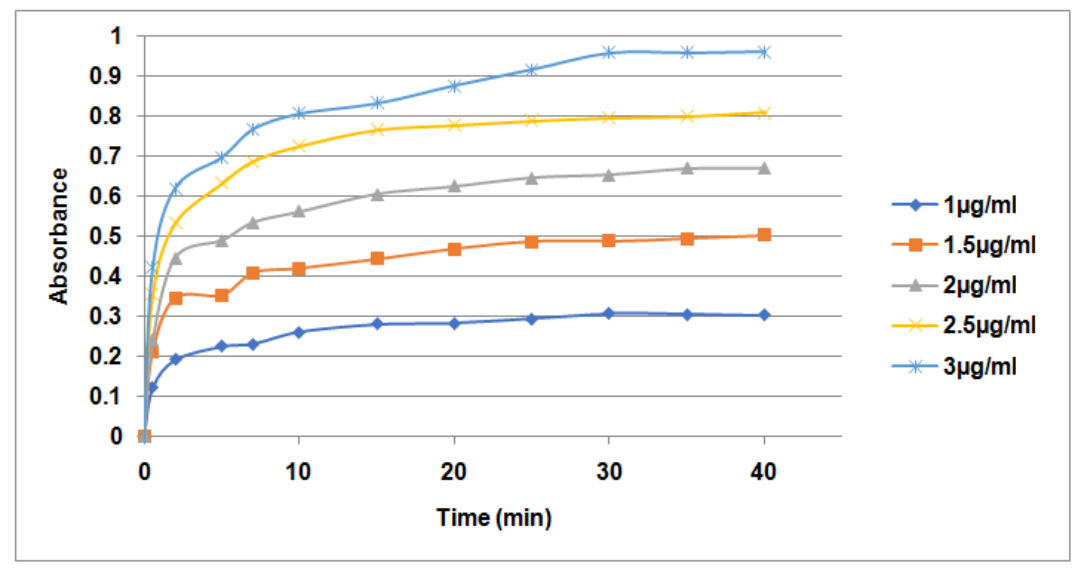

Fig. 7: Absorbance-time curve for the oxidation reaction of methimazole (1-3 $\mu \mathrm{g} / \mathrm{ml})$ by Ce (IV) in acidic medium

From the graphs shown (fig. 7), the rate increases with increasing methimazole concentration, indicating that the reaction rate obeys the rate law equation stating:

$$
\text { Rate }=\mathrm{k}^{\prime}[\mathrm{C}]^{\mathrm{n}}
$$

Where $\mathrm{k}^{\prime}$ is the pseudo-order rate constant and $\mathrm{n}$ is the order of the reaction.

From the graphs shown (fig. 7), the rate of the reaction may be estimated by the variable-time method, measured as $\Delta \mathrm{A} / \Delta \mathrm{t}$ where $\mathrm{A}$ is the absorbance value and $t$ is the time in seconds. Taking logarithms of rates and concentrations, the equation is transformed into:

$$
\log \text { rate }=\log \mathrm{k}^{\prime}+\mathrm{n} \log \mathrm{C}
$$

Regression of $\log$ (rate) versus $\log [\mathrm{C}]$ by least square method generates the calibration equation of:

$$
\log \text { rate }=1.024 \log \mathrm{C}+1.424 \quad \mathrm{r}=0.997
$$

With $\mathrm{k}^{\prime}=26.55 \mathrm{~s}^{-1}$, correlation coefficient $(\mathrm{r})=0.997$ and the reaction is pseudo first order $(\mathrm{n} \approx 1)$ with respect to methimazoleffg. 8). 


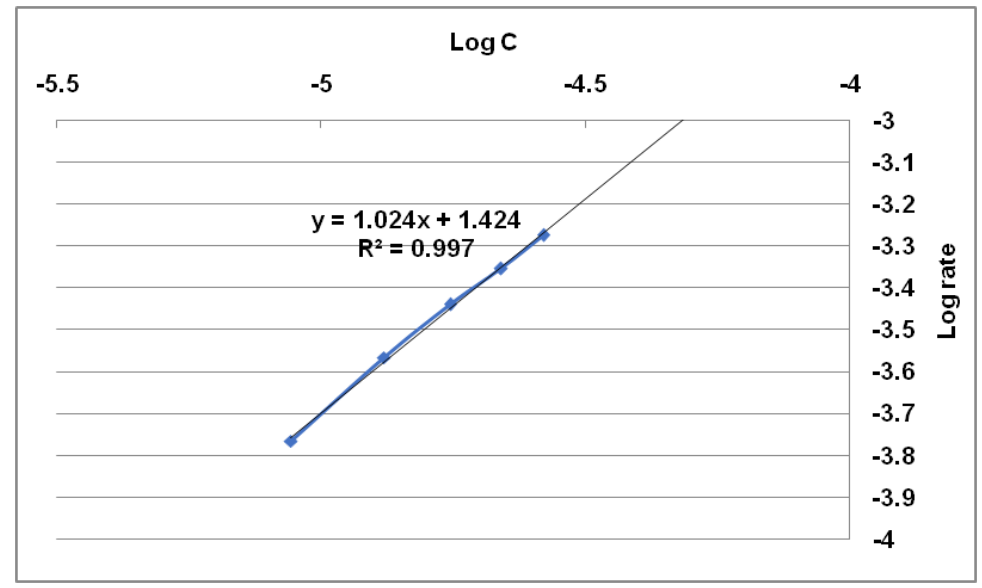

Fig. 8: $\log$ rate versus $\log C$ of methimazole

Under the optimized conditions, the quantitation of methimazole would result in pseudo-first-order reaction rate with respect to its concentration. However, the reaction is pseudo-zero order with respect to Ce (IV) and methyl orange as methimazole concentration was determined using an excess amount of Ce (IV) and methyl orange, $5 \mathrm{mg} \%$ and $0.6 \mathrm{mg} \%$, respectively.

Therefore, the rate will be directly proportional to methimazole concentration in a pseudo-first-order rate equation as follows:

$$
\text { Rate }=\mathrm{k}^{\prime}[\mathrm{C}]^{\mathrm{n}}
$$

Where $\mathrm{k}^{\prime}$ is the pseudo-first-order rate constant.

This equation was the core equation for several experiments that were conducted to obtain methimazole concentration. For this reason, the rate constant, initial rate, fixed absorbance, and fixedtime methods were performed. Based on the applicability, the sensitivity, the correlation coefficient ( $r$ ) and the intercept, the most suitable analytical method was selected.

\section{Rate constant method}

It was performed by plotting graphs of logarithms of absorbance values versus time for different methimazole concentrations in the range of $1-3 \mu \mathrm{g} / \mathrm{ml}$. rectilinear graphs were obtained having a slope of the line $k^{\prime} /-2.303$. Pseudo-first-order rate constants corresponding to different methimazole concentration were calculated from slopes and are presented in table 1.

Regression of methimazole concentration versus $\mathrm{k}^{\prime}$ gave the following equation:

$$
\mathrm{k}^{\prime}=98.46 \mathrm{C}-0.019 \quad \mathrm{r}=0.257
$$

The value of the correlation coefficient (r) indicates poor linearity which is probably due to inconsistency of $\mathrm{k}^{\prime}$ making the method not applicable.

\section{Initial rate method}

The initial rate of reaction would follow a pseudo order rate constant and obey the following rate equation:

$$
\vartheta=\frac{\Delta \mathrm{A}}{\Delta \mathrm{t}}=\mathrm{k}^{\prime}[\mathrm{C}]^{\mathrm{n}}
$$

It was determined by measuring the initial tangents of the absorbance-time curves slopes at different concentration levels (table 2).

Table 1: Values of k', calculated from slopes of $\log$ A versus time graphs multiplied by (-2.303) for different methimazole concentrations

\begin{tabular}{ll}
\hline Concentration (M) & $\mathbf{k}^{\prime}\left(\mathbf{s}^{-1}\right)$ \\
\hline $8.76 \times 10^{-6}$ & -0.01863 \\
$1.31 \times 10^{-5}$ & -0.01652 \\
$1.75 \times 10^{-5}$ & -0.0187 \\
$2.19 \times 10^{-5}$ & -0.01565 \\
$2.63 \times 10^{-5}$ & -0.01691 \\
\hline
\end{tabular}

Table 2: Values of slopes of initial tangents for different methimazole concentrations

\begin{tabular}{ll}
\hline Concentration (M) & Slope $\left(\mathbf{s}^{-1}\right)$ \\
\hline $8.76 \times 10^{-6}$ & 0.00597 \\
$1.31 \times 10^{-5}$ & 0.01055 \\
$1.75 \times 10^{-5}$ & 0.01162 \\
$2.19 \times 10^{-5}$ & 0.01745 \\
$2.63 \times 10^{-5}$ & 0.02077 \\
\hline
\end{tabular}

A calibration curve was constructed by plotting the logarithm of the initial rates $(\Delta \mathrm{A} / \Delta \mathrm{t})$ versus the logarithm of the concentration, and gave the equation:

$$
\log \vartheta=1.103 \log C+3.367 \quad r=0.971
$$

The value of the correlation coefficient $(r)$ indicates poor linearity suggesting that the first step is too fast and not rate-determining, in addition, the graphs were not easy to plot.

\section{Fixed absorbance method}

It was performed by measuring the time required for methimazole concentration to reach an absorbance of a preselected value $(0.45)$ as it gives the widest calibration range. The reciprocals of time $(1 / \Delta t)$ were plotted against the initial concentration of methimazole. The regression equation was obtained (table 3). 
Table 3: Values of $1 / \Delta t$ taken at fixed absorbance $(0.45)$ for different methimazole concentrations

\begin{tabular}{lllcc}
\hline $\boldsymbol{\Delta} \mathbf{t}(\mathbf{s})$ & $\mathbf{1} / \boldsymbol{\Delta t} \mathbf{( \mathbf { s } ^ { - 1 } )}$ & Conc. $(\mathbf{M})$ & Regression equation & Regression coefficient \\
\hline 990 & 0.00101 & $1.31 \times 10^{-5}$ & $\frac{1}{\Delta t}=2033 C-0.026$ & $\mathrm{r}=0.989$ \\
126 & 0.007937 & $1.75 \times 10^{-5}$ & & \\
60 & 0.016667 & $2.19 \times 10^{-5}$ & & \\
36 & 0.027778 & $2.63 \times 10^{-5}$ & & \\
\hline
\end{tabular}

The value of the correlation coefficient indicates poor linearity, and therefore this method cannot be used.

\section{Fixed time method}

It was performed by measuring the absorbance value of the reaction solution containing different methimazole concentrations at a pre- selected fixed time, which was accurately determined. Calibration graphs of absorbance value versus initial concentration of methimazole were established at fixed times of $2,5,10,15,20,25$, 30 and 35 min (table 4).

Table 4: Regression equations at different fixed times for methimazole in the concentration range of $0.25-3 \mu \mathrm{g} / \mathrm{ml}$

\begin{tabular}{lll}
\hline Time (min) & Regression equation & Correlation coefficient \\
\hline 2 & $\mathrm{y}=0.208 \mathrm{x}+0.011$ & 0.983 \\
5 & $\mathrm{y}=0.244 \mathrm{x}-0.008$ & 0.987 \\
10 & $\mathrm{y}=0.279 \mathrm{x}-0.004$ & 0.990 \\
15 & $\mathrm{y}=0.285 \mathrm{x}+0.015$ & 0.982 \\
20 & $\mathrm{y}=0.298 \mathrm{x}+0.009$ & 0.989 \\
25 & $\mathrm{y}=0.308 \mathrm{x}+0.009$ & 0.993 \\
30 & $\mathrm{y}=0.320 \mathrm{x}-0.001$ & 0.999 \\
35 & $\mathrm{y}=0.322 \mathrm{x}+0.001$ & 0.995 \\
\hline
\end{tabular}

The slope is increasing with time while the intercept is decreasing. The most acceptable value of the correlation coefficient was obtained after a fixed time of $30 \mathrm{~min}$; hence the time of $30 \mathrm{~min}$ was chosen as the most suitable time for measurement and calibration construction. Therefore, the fixed time method was the kinetic method selected to calculate the concentration of methimazole through its oxidation.

\section{Method validation}

Linearity, concentration range, the limit of detection and limit of quantitation

Under the optimum reaction conditions, the standard calibration curve was constructed. The linear regression equations were obtained by the least-squares method; a linear correlation was found between the absorbance value at $\lambda_{\max }$ and methimazole concentration.

Linearity parameters including the correlation coefficient, intercept and slope for the calibration data are summarized in table 5. For accurate determination, sensitivity parameters such as apparent molar absorptivity and Sandell's sensitivity values, as well as the limits of detection and quantification, were calculated as per the current ICH guidelines [41] and illustrated in table 5 .

Statistical data suggest the methods to be highly sensitive; reflected by the high molar absorptivity and low Sandell sensitivity values.

Table 5: Assay parameters for the spectrophotometric determination of methimazole

\begin{tabular}{lll}
\hline Parameter & Method A & Method B \\
\hline$\lambda_{\max }$ & $610 \mathrm{~nm}$ & $507 \mathrm{~nm}$ \\
Beer's law limits $(\mu \mathrm{g} / \mathrm{ml})$ & $1.5-15$ & $0.25-3$ \\
Molar absorptivity $(\mathrm{L} / \mathrm{molcm})$ & $6.78798 \times 10^{3}$ & $3.6597 \times 10^{4}$ \\
Sandell sensitivity & 0.0168 & 0.0032 \\
$\mathrm{LOD}(\mu \mathrm{g} / \mathrm{ml})$ & 0.466 & 0.05 \\
$\mathrm{LOQ}(\mu \mathrm{g} / \mathrm{ml})$ & 1.413 & 0.15 \\
Regression equation & & -0.00126 \\
Intercept $(\mathrm{a}) \pm \mathrm{SD}$ & -0.00815 & 0.3205 \\
Slope $(\mathrm{b}) \pm \mathrm{SD}$ & 0.059455 & 0.9998 \\
Correlation coefficient $(\mathrm{r})$ & 0.9993 & 0.0045 \\
$\mathrm{~S}_{\mathrm{a}}$ & 0.0078 & 0.0023 \\
$\mathrm{~S}_{\mathrm{b}}$ & 0.0008 & 0.0048 \\
$\mathrm{~S}_{\mathrm{y} / \mathrm{x}}$ & 0.0084 & \\
\hline
\end{tabular}

\section{Accuracy and precision}

The accuracy of the methods was determined by calculating the $\%$ recovery of methimazole using the standard addition method at three different concentration levels within the linearity range. Percentage recoveries were then calculated and summarized in table 6 for method $\mathrm{A}$ and in table 7 for method B. The obtained \% recoveries show that the method has adequate accuracy.

The precision of the method was expressed in the form of inter-and intra-day as percentage relative standard deviation (\% RSD) for a series of measurements. The precision of the method was verified by repeatability and intermediate precision studies. Repeatability studies were performed by analyzing three different standard solutions, three times each on the same day (intra-day analysis). The intermediate precision of the methods was checked by repeating studies on three different days (inter-day analysis). The results obtained in table 6 for method A and table 7 for method B show good precision of the method.

\section{Method application}

The applicability of the proposed methods was tested in the pharmaceutical formulation Tapazole ${ }^{\circledR}$ tablet. Satisfactory 
percentage recovery was obtained with low \% RSD (table 8). This indicates high accuracy and precision in the determination of methimazole in its commercial tablets. Table 8 represents a statistical comparison between the assay of methimazole in its tablets by the proposed methods and a reference method [21] by means of Student's t-test for accuracy and F-tests for precision at $95 \%$ confidence level. The calculated $\mathrm{t}$ and $\mathrm{F}$ values did not exceed the theoretical values, indicating any significant difference in accuracy and precision between the proposed method and the reference method [21]

Table 6: Accuracy and precision data for the spectrophotometric determination of methimazole in pure form with KMnO4 in alkaline medium

\begin{tabular}{|c|c|c|c|c|c|}
\hline & Methimazole taken $(\mu \mathrm{g} / \mathrm{ml})$ & Methimazole found $(\mu \mathrm{g} / \mathrm{ml})$ & $\%$ RSD & \% Recovery & \% Error \\
\hline \multirow[t]{3}{*}{ Inter-day } & 5 & 5.01 & 6.67 & 100.20 & 0.20 \\
\hline & 10 & 10.22 & 2.29 & 102.20 & 2.20 \\
\hline & 15 & 14.95 & 2.01 & 99.67 & 0.33 \\
\hline \multirow[t]{3}{*}{ Intra-day } & 5 & 5.17 & 3.65 & 103.40 & 3.40 \\
\hline & 10 & 10.05 & 0.87 & 100.50 & 0.50 \\
\hline & 15 & 15.05 & 1.36 & 100.33 & 0.33 \\
\hline
\end{tabular}

Table 7: Accuracy and precision data for the determination of methimazole in pure form using the proposed spectrophotometric method

\begin{tabular}{|c|c|c|c|c|c|}
\hline & Methimazole taken $(\mu \mathrm{g} / \mathrm{ml})$ & Methimazole found $(\mu \mathrm{g} / \mathrm{ml})$ & \%RSD & \% Recovery & \% Error \\
\hline \multirow[t]{3}{*}{ Intra-day } & 1 & 1.017 & 2.906 & 101.70 & 1.70 \\
\hline & 1.5 & 1.537 & 2.367 & 102.47 & 2.47 \\
\hline & 2 & 2.050 & 2.010 & 102.50 & 2.50 \\
\hline \multirow[t]{3}{*}{ Inter-day } & 1 & 1.006 & 1.299 & 100.60 & 0.60 \\
\hline & 1.5 & 1.544 & 3.008 & 102.93 & 2.93 \\
\hline & 2 & 2.073 & 3.518 & 103.65 & 3.65 \\
\hline
\end{tabular}

Table 8: Determination of methimazole in pharmaceutical preparation using methods A and B

\begin{tabular}{llll}
\hline & Method A & Method B & Reference method [21] \\
\hline a Mean \% Recovery \pm SD & $100.82 \pm 0.28$ & $99.85 \pm 1.00$ & $101.78 \pm 1.79$ \\
b\%RSD & 0.28 & 1.00 & 1.77 \\
cError & 0.82 & 0.15 & 1.78 \\
& t-value $=0.294381$ & t-value $=0.233565$ & F-value $=0.475271$ \\
\hline
\end{tabular}

${ }^{a}$ mean \pm SD for five determinations, ${ }^{b}$ Relative standard deviation, cRelative error, ${ }^{* *}$ Theoretical values of $\mathrm{t}$-and $\mathrm{F}$-test at $\mathrm{P}=0.05$ are 2.13 and 5.05 , respectively

\section{CONCLUSION}

Two spectrophotometric colorimetric methods have been developed and validated for the analysis of methimazole. The quantification of methimazole through these two methods accomplishes the requirements of specificity, precision, and accuracy in order to be used for the quality control of pharmaceuticals. These methods can be applied for the quality control of methimazole based on the simplicity, applicability of the parameters, accessibility of the reagents employed and reasonably low time of analysis. The proposed methods based on redox reaction were able to quantify the studied drug in its pharmaceutical formulation without the interference from commonly used excipients.

\section{FUNDING}

Nil

\section{AUTHORS CONTRIBUTIONS}

Malak Y. Al Bathish designed and performed the experiments and the measurements. Azza A. Gazy was involved in planning and supervised the work. Malak Y. Al Bathish and Azza A. Gazy processed the experimental data along with the calculations, designed the fig. and interpreted the results. Malak Y. Al Bathish, Azza A. Gazy and Marwa K. El Jamal revised the results and drafted the manuscript.

\section{CONFLICTS OF INTERESTS}

The authors declare that there are no conflicts of interest.

\section{REFERENCES}

1. USP US. Pharmacopoeia-National Formulary [USP 38 NF 33]. Rockville, Md United States Pharmacopeial Conv; 2015.
2. Garcia MS, Albero MI, Sanchez Pedreno C, Tobal L. Kinetic determination of carbimazole, methimazole and propylthiouracil in pharmaceuticals, animal feed and animal livers. Analyst 1995;120:129-33.

3. Sanchez Pedreño C, Albero MI, Garcia MS, Rodenas V. Flowinjection spectrophotometric determination of carbimazole and methimazole. Anal Chim Acta 1995;308:457-61.

4. Dong C, Zhang Y, Guo L, Li Q. Spectrophotometric determination of methimazole in pharmaceutical, serum and urine samples by reaction with potassium ferricyanide-Fe(III). J Anal Chem 2010;65:707-12.

5. Tu CQ, Wen XR. Indirect determination of methimazole in a pharmaceutical sample by discoloration spectrophotometry using Fe (III)-tiron system. Adv Mater Res 2013;781-784:115-9.

6. Rahmani A. Sensitive photometric method for the assay of methimazole in pure and pharmaceutical formulations; 2015. p. 64-7.

7. Chipiso K, Simoyi RH. Kinetics and mechanism of oxidation of methimazole by chlorite in slightly acidic media. J Phys Chem A 2016;120:3767-79.

8. El-Bardicy MG, El-Saharty YS, Tawakkol MS. Determination of carbimazole and methimazole by first and third derivative spectrophotometry. Spectrosc Lett 1991;24:1079-95.

9. Min H, Zeng Ping C, Yao C, Cai Xia S, Ru-Qin Y. Quantification of methimazole in plasma and tablet samples by surfaceenhanced raman spectroscopy in combination with the multiplicative effects model. Chinese J Anal Chem 2015;43:759-64.

10. Saleh TA, Al-Shalalfeh MM, Al-Saadi AA. Graphene dendrimerstabilized silver nanoparticles for the detection of methimazole 
using surface-enhanced raman scattering with the computational assignment. Sci Rep 2016;6:32185.

11. Liu X, Yuan H, Pang D, Cai R. Resonance light scattering spectroscopy study of interaction between gold colloid and thiamazole and its analytical application. Spectrochim Acta Part A Mol Biomol Spectrosc 2004;60:385-9.

12. Economou A, Tzanavaras PD, Notou M, Themelis DG. Determination of methimazole and carbimazole by flowinjection with chemiluminescence detection based on the inhibition of the $\mathrm{Cu}(\mathrm{II})$-catalysed luminol-hydrogen peroxide reaction. Anal Chim Acta 2004;505:129-33.

13. Sheng Z, Han H, Yang G. A novel method for sensing of methimazole using gold nanoparticle-catalyzed chemiluminescent reaction. Luminescence 2011;26:196-201.

14. Kong D, Li Q, Jiang J, Xinyu Z, Xuechou Z, Chi Y, et al. Flow injection analysis of thiamazole based on strong $\mathrm{Ru}(\mathrm{bpy}) 3$ $2+$ co-reactant electrochemiluminescence. Luminescence 2015 30:12-7.

15. Dong F, Hu K, Han H, Liang J. A novel method for methimazole determination using CdSe quantum dots as fluorescence probes. Microchim Acta 2009;165:195-201.

16. Farzampour L, Amjadi M. Sensitive turn-on fluorescence assay of methimazole based on the fluorescence resonance energy transfer between acridine orange and silver nanoparticles. J Lumin 2014;155:226-30.

17. Sun J, Zheng C, Xiao X, Niu L, You T, Wang E. Electrochemical detection of methimazole by capillary electrophoresis at a carbon fiber microdisk electrode. Electroanalysis 2005;17:1675-80.

18. Wang JP, Tang WW, Fang GZ, Pan MF, Wang S. Development of a biomimetic enzyme-linked immunosorbent assay method for the determination of methimazole in urine sample. J Chinese Chem Soc 2011;58:463-9.

19. Pan M, Fang G, Lu Y, Kong L, Yang Y, Wang S. Molecularly imprinted biomimetic QCM sensor involving a poly(amidoamine) dendrimer as a functional monomer for the highly selective and sensitive determination of methimazole. Sensors Actuators B Chem 2015;207:588-95.

20. Aletrari M, Kanari P, Partassides D, Loizou E. Study of the British pharmacopeia method on methimazole (thiamazole) content in carbimazole tablets. I Pharm Biomed Anal 1998;16:785-92.

21. Hollosi L, Kettrup A, Schramm KW. MMSPE-RP-HPLC method for the simultaneous determination of methimazole and selected metabolites in fish homogenates. J Pharm Biomed Anal 2004;36:921-4.

22. Kusmierek K, Bald E. Determination of methimazole in urine by liquid chromatography. Talanta 2007;71:2121-5.

23. Zakrzewski R. Determination of methimazole in pharmaceutical preparations using an HPLC method coupled with an iodine-azide post-column reaction. J Liq Chromatogr Relat Technol 2008;32:383-98.

24. Zakrzewski R. Determination of methimazole in urine with the iodine-azide detection system following its separation by reversed-phase high-performance liquid chromatography. J Chromatogr B 2008;869:67-74.

25. Pan M, Wang J, Fang G, Tang W, Wang S. Synthesis and characterization of a molecularly imprinted polymer and its application as SPE enrichment sorbent for determination of trace methimazole in pig samples using HPLC-UV. J Chromatogr B 2010;878:1531-6.
26. Xi X, Ming L, Liu J. Electrochemical determination of thiamazole at a multi-wall carbon nanotube modified glassy carbon electrode. J Appl Electrochem 2010;40:1449-54.

27. Yazhen W. Electrochemical determination of methimazole based on the acetylene black/chitosan film electrode and its application to rat serum samples. Bioelectrochemistry 2011;81:86-90.

28. Kutluay A, Aslanoglu M. Multi-walled carbon nanotubes/electro-copolymerized cobalt nanoparticlespoly(pivalic acid) composite film coated glassy carbon electrode for the determination of methimazole. Sensors Actuators B Chem 2012;171-172:1216-21.

29. Jalali F, Miri L, Roushani M. Electrocatalytic determination of anti-hyperthyroid drug, methimazole, using a modified carbonpaste electrode. African J Pharm Pharmacol 2013;7:269-74.

30. Fouladgar M, Mohammadzadeh S. Determination of methimazole on a multiwall carbon nanotube titanium dioxide nanoparticle paste electrode. Anal Lett 2014;47:763-77.

31. Norouzi P, Gupta VK, Larijani B, Ganjali MR, Faridbod F. A new methimazole sensor based on a nanocomposite of CdS NPsRGO/IL-carbon paste electrode using differential FFT continuous linear sweep voltammetry. Talanta 2014;127:94-9.

32. Dorraji PS, Jalali F. Sensitive amperometric determination of methimazole based on the electrocatalytic effect of rutin/multiwalled carbon nanotube film. Bioelectrochemistry 2015;101:66-74.

33. Si W, Han Z, Lei W, Wu Q, Zhang Y, Xia M, et al. Fast electrochemical determination of imidacloprid at an activated glassy carbon electrode. J Electrochem Soc 2014;161:B9-13.

34. Rahman N, Anwar N, Kashif M, Hoda MN, Rahman H. Determination of labetalol hydrochloride by kinetic spectrophotometry using potassium permanganate as oxidant. J Mex Chem Soc 2011;55:105-12.

35. Wahed MGA, Sheikh R El, Gouda AA, Taleb SA. Kinetic spectrophotometric determination of some fluoroquinolone antibiotics in bulk and pharmaceutical preparations. Bull Chem Soc Ethiop 2013;27:329-46.

36. Reddy KD, Sayanna K, Venkateshwarlu G. Kinetic spectrophotometric determination of drugs based on oxidation by alkaline KMno4. J Appl Chem 2014;6:8-14.

37. Darwish IA, Khedr AS, Askal HF, Mohamed RM. Application of inorganic oxidants to the spectrophotometric determination of ribavirin in bulk and capsules. J AOAC Int 2006;89:341-51.

38. Krebs A, Starczewska B, Puzanowska Tarasiewicz H, Sledz J. Spectrophotometric determination of olanzapine by its oxidation with $\mathrm{N}$-bromosuccinimide and cerium (IV) sulfate. Anal Sci 2006;22:829-33.

39. Abdellatef HE, El-Henawee MM, El-Sayed HM, Ayad MM. Spectrophotometric and spectrofluorimetric methods for the analysis of acyclovir and acebutolol hydrochloride. Spectrochim Acta Part A Mol Biomol Spectrosc 2006;65:997-9.

40. David IG, David V, Ciucu AA, Ciobanu A. Indirect spectrophotometric determination of neomycin based on the reaction with cerium (IV) sulfate. Department Phys Chem 2010;19:61-8

41. ICH. Validation of analytical procedures: text and methodology Q2(R1). International Conference on Harmonization of Technical Requirements for Registration of Pharmaceuticals for Human Use; 2005.

42. John Rose. Advanced Physicochemical Experiments. Pitman Publishing; 1964. 